\title{
Telemedicine and e-health in Algeria facing challenges in medical practice
}

\author{
Type of article: conference Abstract
}

\author{
Zoubir Sari, Souhil Tliba, Mohamed Zeroug, Wahiba Mammeri-Oussediks \\ Société Algérienne de Télémédicine et de e-Santé (SATeS) \\ ZoubirSari@hotmail.com
}

\begin{abstract}
The Algerian health system operates in a demographic, economic, environmental, and societal specific context to meet the challenges of epidemiological transition. Development of information and communication technologies in this atmosphere allow telemedicine and ehealth emergence in the vast country of Algeria. Thus, the country may face these challenges by including them in a national telemedicine plan and making a major focus of global action for the prevention and control of prevalent diseases. The interest to adopt this tool in daily practice stems from an improvement in the quality of communication between practitioners and in the doctor-patient relationship with a possibility of quick access to care and more efficient care pathways. Thus, national goals in fight plans against diseases will be achieved. Telemedicine and e-health projects that methodologically well-defined, respecting regulations and using all means and all available resources, including WHO mobile health, are to be designed and implemented in all areas, especially in the national plan against notcommunicated diseases, maternal and child health, old aging health, and mental health. This approach will integrate telemedicine in the health care system whose inevitable implementation can be done on solid foundations and will be actively supported by SATeS.
\end{abstract}

Keywords: Diagnostic, Telemedicine, e-health, Medical practice.

\section{Declaration of conflicts}

This article was selected from ICHSMT'16 abstract book.

\section{Authors' biography}

No Biography

3. References

No reference 